\title{
Water-insoluble polymer-free uniform nanofibers of peracetylated cyclodextrin by electrospinning
}

\author{
Fuat Topuz $^{1, *}$ (1), Ashif Y. Shaikh ${ }^{1}$, Mustafa O. Guler ${ }^{2}$, and Tamer Uyar ${ }^{1,3, *}$ (1) \\ ${ }^{1}$ Institute of Materials Science and Nanotechnology, UNAM-National Nanotechnology Research Center, Bilkent University, \\ 06800 Ankara, Turkey \\ ${ }^{2}$ Pritzker School of Molecular Engineering, University of Chicago, Chicago, IL 60637, USA \\ ${ }^{3}$ Department of Fiber Science and Apparel Design, College of Human Ecology, Cornell University, Ithaca, NY 14853, USA
}

Received: 12 March 2020

Accepted: 11 May 2020

Published online:

26 May 2020

(C) Springer Science+Business Media, LLC, part of Springer Nature 2020

\begin{abstract}
Hydrophobic cyclodextrin (CD) nanofibers were produced by the electrospinning of peracetylated $\beta$-CD without requiring any polymer as a carrier matrix. Native $\beta$-CD was peracetylated through the reaction with acetic anhydride, and the conversion of all hydroxyl groups into acetyl was confirmed by NMR, XPS, and TGA analyses. The peracetyl modification drastically boosted the thermal stability of the $\beta$-CD molecules. The electrospinning of the peracetylated $\beta$-CD from its highly concentrated solutions $(180 \%(\mathrm{w} / \mathrm{v}))$ in DMF led to bead-free nanofibers, while electrospinning at the concentrations of 140 and $160 \%(\mathrm{w} / \mathrm{v})$ CDs resulted in beads and beaded nanofibers, respectively. The electrospinning process parameters such as applied voltage, flow rate, and tip-to-collector distances were systematically altered to produce a uniform nanofiber structure. The flow rate had the most drastic effect on the diameter and morphology of the resultant nanofibers: A threefold rise in the fiber diameter was observed with increasing the flow rate from 0.1 to $2 \mathrm{~mL} \mathrm{~h}^{-1}$. Similarly, higher electrical field increased the fiber diameter due to higher mass flow, while boosting the tip-tocollector distance did not reveal any significant change on the fiber diameter. The stability of the peracetylated $\beta$-CD nanofibers was observed in water for $24 \mathrm{~h}$ without any significant morphological change; however, the dissolution of the nanofiber mat was observed with a long-time exposure to water. We demonstrated production of hydrophobic uniform CD nanofibers without using any carrier polymer.
\end{abstract}

Address correspondence to E-mail: fuat.topuz@rwth-aachen.de; tu46@cornell.edu 


\section{Introduction}

Cyclodextrin (CD) is a class of cyclic oligomers of glucose produced by the enzymatic degradation of starch with a unique toroidal shape whose interior is partially hydrophobic, while the exterior is hydrophilic owing to the presence of many hydroxyl groups [1, 2]. This unique structure with an intrinsic hydrophobic cavity interior allows inclusion complexation with hydrophobic molecules that are small enough to fit into the cage cavity and enhances their water solubility [3-5]. Furthermore, their non-toxic, inexpensive, and edible structures make them promising compounds for a broad spectrum of applications, ranging from textile [6] to biomedical applications [7].

Cyclodextrins (CDs) have been engineered in various material forms to be exploited in the environment [8], drug/gene delivery [9, 10], tissue engineering [11], textile industry [12], and food industry [13]. They could be electrospun into nanofibers without requiring any carrier polymer thanks to the presence of many hydrogen bonds [14-18]. However, the resultant nanofibers dissolve instantly in contact with water owing to their hydrophilic and uncross-linked structure. Thus, efficient cross-linking mechanisms were required for their structural stabilization in aqueous media. In this regard, the last decade has witnessed significant advances in the production of $C D$ nanofibers and their cross-linking with impregnated cross-linkers (e.g., butanetetracarboxylic acid (BTCA) [19] and epichlorohydrin [8]). Even though such chemical cross-linking leads to very stiff, insoluble poly-CD nanofibers, which do not show any drastic difference in the nanofiber morphology upon exposure to various solvents, including water, could efficiently be exploited for the scavenging of methylene blue [19], phenanthrene [8], phenolphthalein [8], polycyclic aromatic hydrocarbons [20], and heavy metals [20] from aqueous solutions. However, the cross-linking of the fibers requires a post-heat treatment step at a very high temperature $\left(>150{ }^{\circ} \mathrm{C}\right)$ for a couple of hours to able to connect $\mathrm{CD}$ molecules over hydroxyl groups $[8,20]$. Thus, there is an increasing demand for simple but efficient routes in the engineering of hydrophobic $\mathrm{CD}$ nanofibers that do not require any post-heat treatment process for the network stabilization.
CD molecules have been modified with different functional motifs over primary or secondary hydroxyl groups [21]. In this regard, direct and indirect routes can be followed: For instance, hydroxyl groups can be protected as benzoate ester and then followed by selective deprotection of the primary alcohol groups, while the other method takes place on the selective activation of the primary hydroxyl groups, such as via a bulky triphenylphosphonium salt, followed by substitution with another functional group. Mainly, the modification of CDs with hydrophobic moieties makes the $\mathrm{CD}$ molecules nonpolar so that the materials composed of such molecules can be employed for water-based applications without requiring a further cross-linking step. In this regard, in one example, $C D$ molecules were functionalized with phenylacetic acid and electrospun into fibers [22]. The presence of $\pi-\pi$ interactions between the phenylacetic acid functional $\mathrm{CD}$ molecules led to stable nanofibers for their use in drug delivery. Likewise, CD molecules could be modified with different functional groups, such as acetyl, which has been accomplished by treating with acetic anhydride in dry pyridine, to be exploited in chiral separation, or as an additive to polyurethane coatings as the polyol [23]. This modification can be done in an ionic liquid (1-butyl-3-methylimidazolium bromide) using acetic anhydride in the absence of catalyst under supercritical $\mathrm{CO}_{2}$ condition [24]. Likewise, Xiao et al. showed the acetylation of the $\beta$-CD in 2,4-dioxane using acetic anhydride and the catalyst 3-picoline [25]. Overall, this chemistry is straightforward and can yield hydrophobic acetyl functional $\beta$-CD molecules of different substitution degrees. Such molecules have been exploited for the sustained release applications, such as delayed release of omeprazole [26].

In this study, we demonstrate water-insoluble CD nanofibers using peracetylated $\beta$-CD molecules. The hydroxyl groups of $\beta$-CD molecules were modified with acetyl groups through the reaction with acetic anhydride, and their solutions in DMF were electrospun into nanofibers without using any carrier polymer. The variations in the electrospinning process variables on the resultant nanofibers properties were studied, and the structural properties of the nanofibers were explored. 


\section{Experimental section}

\section{Materials}

$\beta$-CD was kindly received as a gift from Wacker Chemie AG (Germany). Acetic anhydride ( $\geq 99 \%)$, pyridine (anhydrous, 99.8\%), 4-(dimethylamino)pyridine $(\geq 99 \%$, DMAP), dimethylformamide (DMF), and silver nitrate $\left(\mathrm{AgNO}_{3}, \geq 99.0 \%\right)$ were purchased from Sigma-Aldrich.

\section{Synthesis of peracetylated $\beta$-cyclodextrin}

(PAc- $\beta$-CD). $\beta$-CD ( $1 \mathrm{~g}$ ) was dissolved in dry pyridine $(10 \mathrm{~mL})$, and the solution was cooled down to $0-5{ }^{\circ} \mathrm{C}$. Afterward, acetic anhydride (30 equiv. of $\beta$ $\mathrm{CD})$ and $100 \mathrm{mg}$ of DMAP ( $N, N$-dimethylamino pyridine) were slowly added to this mixture, and the solution kept stirring at RT for $24 \mathrm{~h}$. The excess pyridine was removed by rotovap, and the remaining solution poured into water and mixed vigorously. The precipitated peracetylated $\beta-\mathrm{CD}$ was collected and dried in a vacuum oven. ${ }^{1} \mathrm{H}-\mathrm{NMR}$ of peracetylated $\beta$-CD (PAc- $\beta$-CD) matched with reported data [26].

\section{Electrospinning of the peracetylated $\beta$-CDs}

PAc- $\beta$-CD was dissolved in DMF under continuous stirring and thereafter transferred into a $1-\mathrm{mL}$ disposable plastic syringe $\left(\mathrm{B}\right.$ Braun $^{\mathrm{TM}}$ Injekt $^{\mathrm{TM}}$-F Fine Dosage Syringe) and connected to a blunt needle (Sterican ${ }^{\circledR}$ MIX blunt). A high-voltage power supply (Matsusada Precision (AU Series, Japan)) was used to apply the voltage $(15 \mathrm{kV})$. A syringe pump (model SP 101IZ, WPI, USA) was used to deliver the CD solutions at a fixed rate of $0.5 \mathrm{~mL} \mathrm{~h}^{-1}$. During the electrospinning, the tip-to-collector distance (TCD) was kept at $15 \mathrm{~cm}$, and a square collector plate $(8 \times 8 \mathrm{~cm})$ covered by an aluminum foil was used for the nanofiber deposition. For the electrospinning process variables study, each parameter was altered systematically while keeping other parameters constant. The experiments were performed at $24 \pm 2{ }^{\circ} \mathrm{C}$ and relative humidity of $32 \pm 1 \%$. The mean diameter of the resultant fibers was explored over 100 fibers using the ImageJ software (National Institutes of Health, Bethesda, MD, USA).

\section{Characterization}

Nuclear magnetic resonance (NMR) analysis was performed on a Bruker DPX-400 instrument. ${ }^{1} \mathrm{H}$ NMR analyses were recorded at $400 \mathrm{MHz}$, and a total of 256 scans were taken. Thermal analyses of the $\beta$ $\mathrm{CD}$ before and after acetyl modification were performed by the thermogravimetric analyzer (TGA, TA Q500). TGA measurements were taken under a nitrogen atmosphere from 30 to $600{ }^{\circ} \mathrm{C}$ with a heating rate of $20{ }^{\circ} \mathrm{C} \mathrm{min}^{-1}$. The $\mathrm{X}$-ray photoelectron spectra of the samples were recorded using an $\mathrm{X}$-ray photoelectron spectrometer (K-Alpha X-ray Photoelectron Spectrometer (XPS) System, Thermo Fisher Scientific, UK). As an X-ray source, $\mathrm{Al} K$-alpha X-ray monochromator ( $0.1 \mathrm{eV}$ step size, $12 \mathrm{kV}, 2.5 \mathrm{~mA}$, spot size $400 \mu \mathrm{m}$ ) was exploited at an electron takeoff angle of $90^{\circ}$. The XPS spectra of C $1 \mathrm{~s}$ were measured 30 times, with $50 \mathrm{~ms}$ dwell time (pass energy $30 \mathrm{eV}$ ).

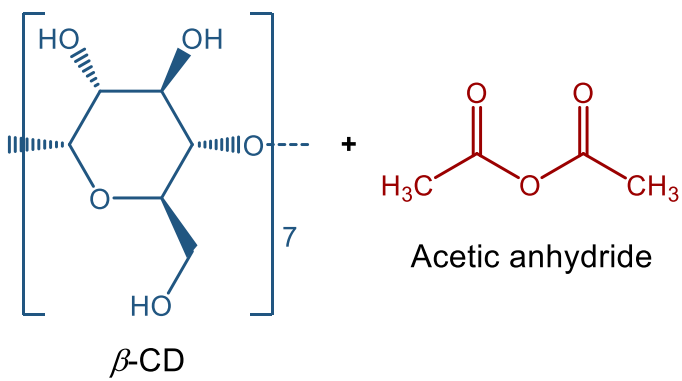

(i) Dry pyridine $0-5^{\circ} \mathrm{C}$

(ii) DMAP / $24 \mathrm{~h}$

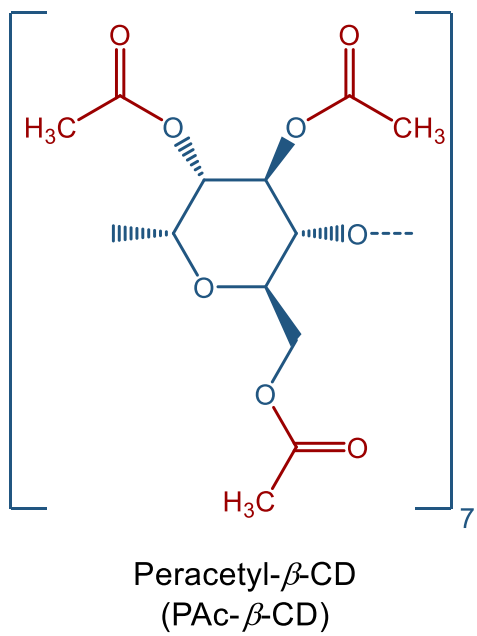

Scheme 1 Synthesis pathway of the peracetylated $\beta$-CD (PAc- $\beta$ CD) molecule from the $\beta$-CD. 


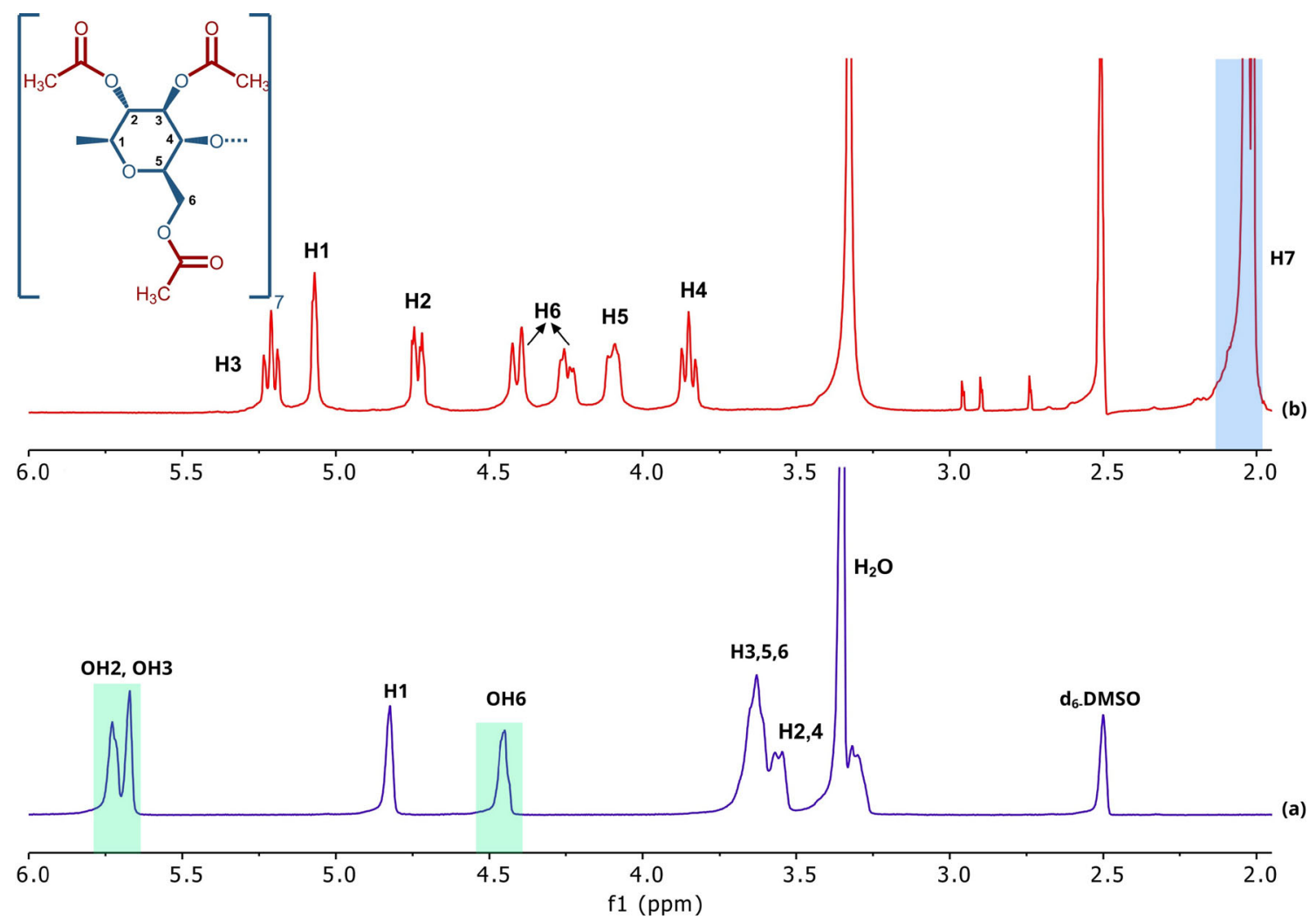

Figure $1{ }^{1} \mathrm{H}$-NMR spectra of $\mathbf{a} \beta$-CD and $\mathbf{b}$ PAc- $\beta$-CD molecules. Inset shows the molecular structure of the PAc- $\beta-\mathrm{CD}$. The proton peaks of the $\mathrm{OH}$ groups of the $\beta-\mathrm{CD}$ at 4.5 and

The morphology of electrospun nanofibers was visualized by scanning electron microscopy (SEM, Quanta FEG 200, FEI). Prior to the SEM analysis, the nanofibers were sputtered with a $5 \mathrm{~nm}$ Au using a PECS sputter system. The mean diameter of the nanofibers was calculated from the corresponding SEM images over $\sim 100$ nanofibers using ImageJ software (ImageJ 1.43j, National Institutes of Health, Bethesda, Maryland, USA). The surface wettability was studied by a contact angle goniometer (OCA20, Dataphysics, Germany). The electrospun mat $(2 \mathrm{~cm} \times 4 \mathrm{~cm})$ was placed on a microscope glass slide and fixed with a tape. A water droplet with a volume of $5 \mu \mathrm{L}$ was dropped onto the mat, and the water contact angle (WCA) of the mat was calculated by the Laplace-Young equation.
$5.7 \mathrm{ppm}$ disappeared after the modification, while a new peak showed up around $2 \mathrm{ppm}$ because of the methyl protons of the acetate groups.

\section{Results and discussion}

PAc- $\beta$-CD was synthesized by reacting $\beta$-CD with acetic anhydride in dry pyridine (Scheme 1). Figure 1 shows the ${ }^{1} \mathrm{H}-\mathrm{NMR}$ spectra of both $\beta$-CD and peracetylated $\beta$-CD. The proton peaks related to the PAc- $\beta$-CD are in line with the previous report [26]. The attachment of acetyl groups to the backbone of $\beta$ $\mathrm{CD}$ was confirmed by the appearance of a proton peak at $2 \mathrm{ppm}$, which can be assigned to the methyl protons of the acetyl groups [24]. Furthermore, the $\mathrm{OH}$ protons of $\beta$-CD at $5.70-5.75$ and $4.4-4.5 \mathrm{ppm}$ disappeared, suggesting the successful peracetylation of the hydroxyl groups of $\beta$-CD.

XPS analysis was also performed to confirm the synthesis of PAc- $\beta$-CD molecules. The respective deconvoluted C1s spectra of both $\beta$-CD and PAc- $\beta$ $\mathrm{CD}$ are shown in Fig. 2a, b. Typically, the $\beta$-CD molecule has three different peaks related to the $\mathrm{C} 1 \mathrm{~s}$ : (i) $\mathrm{C}-\mathrm{C}$ and $\mathrm{C}-\mathrm{H}$ at $284.75 \mathrm{eV}$, (ii) $\mathrm{C}-\mathrm{O}$ at $286 \mathrm{eV}$, and (iii) $\mathrm{C}-\mathrm{O}-\mathrm{C}$ bond at $287.5 \mathrm{eV}$ [8]. Atomic ratios were calculated to be $23.70(\mathrm{C}-\mathrm{C}, \mathrm{C}-\mathrm{H}), 54.76(\mathrm{C}-\mathrm{O})$, and 

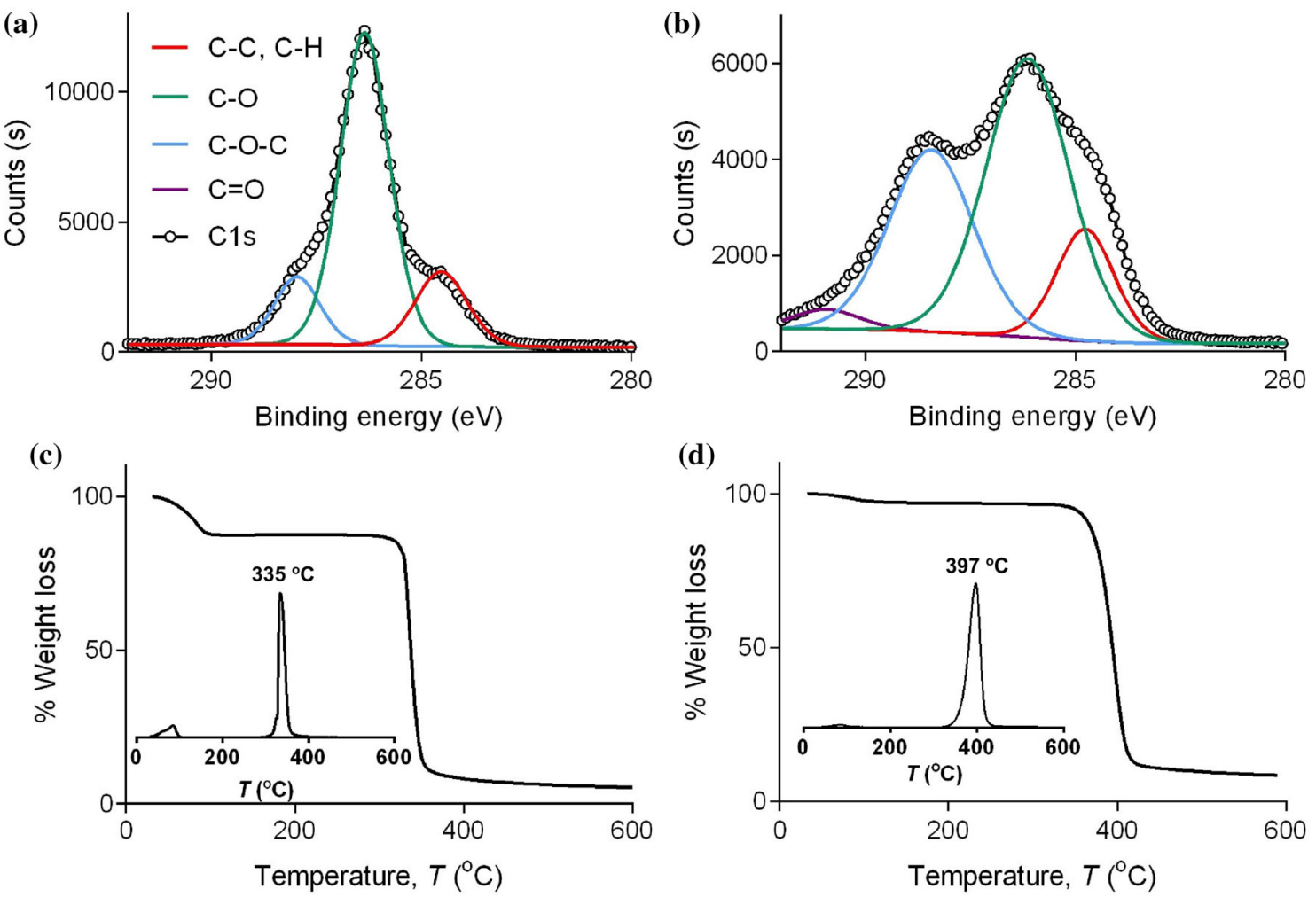

Figure $2 \mathrm{C} 1 \mathrm{~s}$ deconvoluted XPS spectra of $\mathbf{a} \beta$-CD and $\mathbf{b}$ PAc- $\beta$-CD. TGA thermograms of $\mathbf{c} \beta$-CD and $\mathbf{d}$ PAc- $\beta$-CD. Insets show the first derivative of the thermograms.
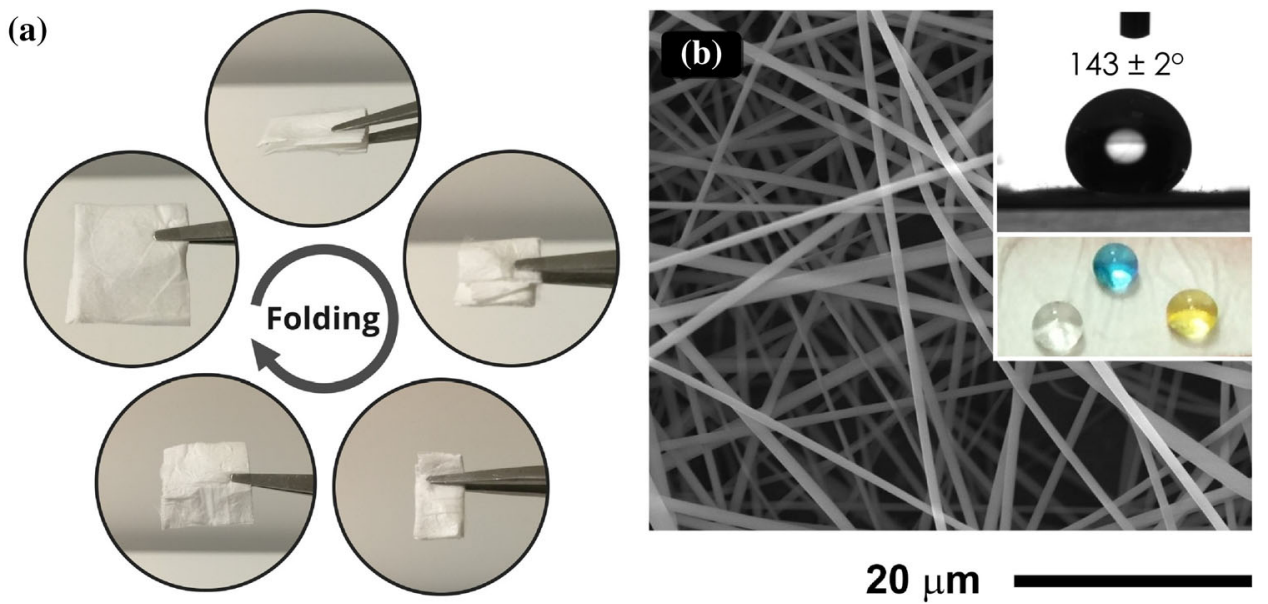

Figure 3 a Photographs of the PAc- $\beta$-CD electrospun mat during the folding/unfolding for many times. $\mathbf{b}$ A scanning electron micrograph of the PAc- $\beta$-CD nanofibers. Insets show the optical

$21.54(\mathrm{C}-\mathrm{O}-\mathrm{C}) \%$. PAc- $\beta$-CD has an additional $\mathrm{C} 1 \mathrm{~s}$ peak due to the presence of $\mathrm{C}=\mathrm{O}$ at $290 \mathrm{eV}$ of the attached acetyl group [25]. Furthermore, after the acetyl functionalization, the atomic ratio of the $\mathrm{C}-\mathrm{O}-$ $C$ peak increased from 21.54 to $30.95 \%$ : The atomic ratios for the PAc- $\beta$-CD were calculated as 12.06 (C- photograph of a water droplet on the electrospun mat, along with the corresponding WCA, as well as the top view of water droplets (i.e., dyed with methylene blue and methyl orange).

$\mathrm{C}, \mathrm{C}-\mathrm{H}), 54(\mathrm{C}-\mathrm{O}), 30.95(\mathrm{C}-\mathrm{O}-\mathrm{C})$, and $3(\mathrm{C}=\mathrm{O}) \%$. The thermal analysis showed that the peracetyl modification of $\beta$-CD molecules significantly enhanced the thermal stability of the $\beta$-CD. With acetyl modification, the thermal decomposition temperature $\left(T_{\mathrm{d}}\right)$ increased from 335 to $397^{\circ} \mathrm{C}$ (Fig. 2c, 
Figure 4 Scanning electron micrographs of the PAc- $\beta$-CD nanofibers produced at various applied voltages: a $10 \mathrm{kV}$, b $15 \mathrm{kV}$, c $20 \mathrm{kV}$, and d $25 \mathrm{kV}$. The flow rate and tipto-collector distance were $0.5 \mathrm{~mL} \mathrm{~h}^{-1}$ and $15 \mathrm{~cm}$. Insets show the size distribution diagrams of the respective nanofibers.

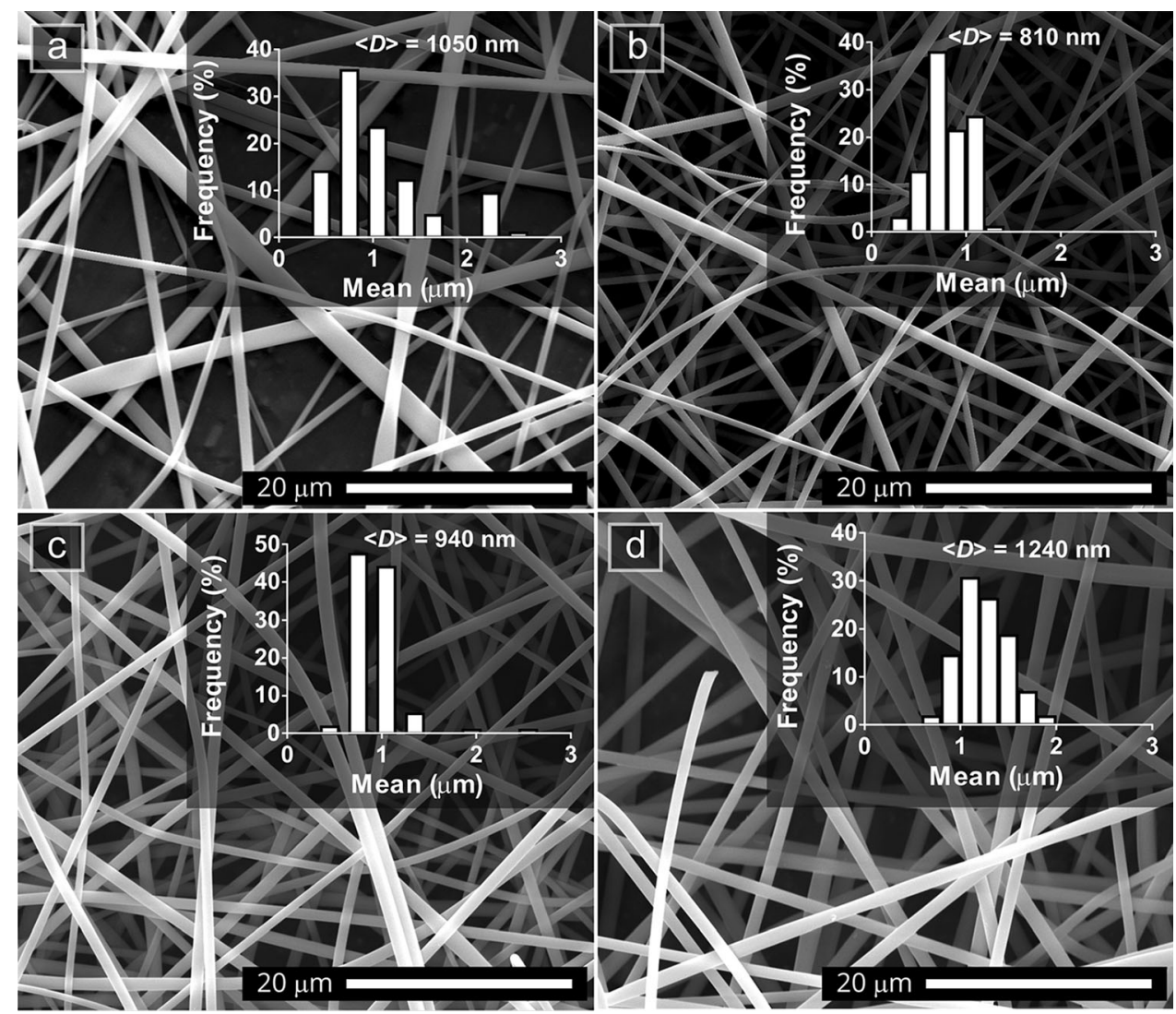

d). Furthermore, the PAc- $\beta$-CD has less adsorbed water content than the $\beta$-CD (i.e., mass loss between before $120{ }^{\circ} \mathrm{C}$ ) owing to the hydrophobic nature of the acetyl groups (Figure $\mathrm{c}, \mathrm{d}$ ).

Because of the hydrophobic character, the PAc- $\beta$ $\mathrm{CD}$ could not dissolve in water $\mathrm{CD}$ could not dissolve in water [26], while it completely dissolved in DMF and formed a highly viscous solution at high CD content $(180 \%(\mathrm{w} / \mathrm{v})$. Figure S1 shows the morphology of electrosprayed and electrospun PAc- $\beta$-CD structures from DMF solutions at various concentrations at the applied voltage of $15 \mathrm{kV}$. At the concentration of $140 \%(\mathrm{w} / \mathrm{v})$, the formation of beads was observed, demonstrating electrospraying took place (Figure S1a). However, with a concentration rise to $160 \%(\mathrm{w} / \mathrm{v})$, the formation of the beaded fibers was observed (Figure S1b). At this concentration, electrospinning took place instead of electrospraying. Further increasing the CD concentration to $180 \%$ (w/ v) led to the bead-free uniform fibers (Figure S1c). The mean diameter of the fibers was calculated as $1690 \pm 490 \mathrm{~nm}$, suggesting the formation of microfibers, along with a small portion of nanofibers. The concentration for the electrospinning of the PAc- $\beta$ -
$\mathrm{CD}$ is higher than polymeric systems, which are generally between 5 and $30 \%(\mathrm{w} / \mathrm{v})$ to able electrospun into bead-free fibers [27, 28]. However, for our case, we do not use any polymeric component, and the overall system is absent from entangled chains to form physical joint domains. Indeed, the electrospinning of $C D$ nanofibers is owing to the presence of hydrogen bonds and other intermolecular interactions, and therefore, the interference of hydrogen bonding agents disturbs their electrospinning and leads to beaded nanofibers [18]. Such high concentrations are used for the electrospinning of hydroxypropyl functional and native CD molecules $[15,16]$. This suggests that acetyl modification does not critically change their electrospinnability.

The electrospinning of the PAc- $\beta$-CD was performed from the DMF solutions (Fig. 3). The resultant electrospun mat could be easily handled and folded many times without any crack development. Despite the polymer-free nature of the CD (Fig. 3b), the electrospinning process led to a freestanding material. The morphology of the fibers was confirmed by SEM analysis, and the formation of beadfree CD fibers was evident. The contact angle 

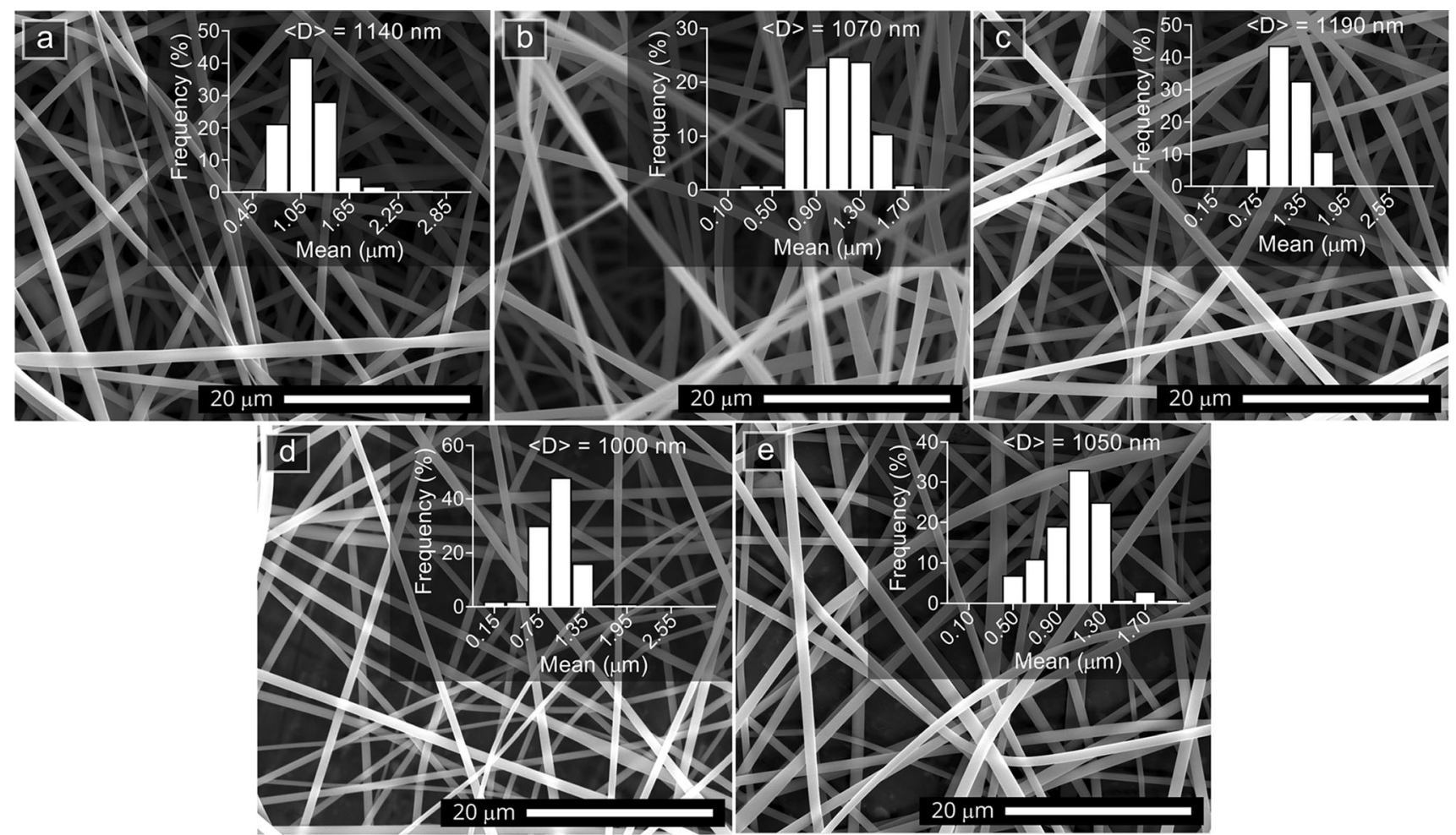

Figure 5 Scanning electron micrographs of the PAc- $\beta-C D$ nanofibers produced at various tip-to-collector distances (TCDs): a $5 \mathrm{~cm}$, b $10 \mathrm{~cm}$, c $15 \mathrm{~cm}, \mathbf{d ~} 20 \mathrm{~cm}$, and e $25 \mathrm{~cm}$. The applied

measurements revealed the hydrophobic nature of the mat. The wettability measurements using distilled water and dyed water with methylene blue and methyl orange revealed rounded morphology with the corresponding WCA of $143 \pm 2^{\circ}$ (Fig. 3c).

When the optimum concentration was determined to obtain bead-free fibers, the electrospinning process variables were optimized to produce uniform fibers from the PAc- $\beta$-CD. A systematic study was performed by changing the electrospinning process variables stepwise while keeping other parameters constant. First, the applied voltage was systematically boosted while keeping other parameters (i.e., flow rate and tip-to-collector distance) constant at $0.5 \mathrm{ml} \mathrm{h}^{-1}$ and $15 \mathrm{~cm}$, respectively. Increasing the applied voltage led to the formation of thicker fibers: The fibers electrospun at $15 \mathrm{kV}$ were $0.81 \pm 0.34 \mu \mathrm{m}$ in diameter, while the fibers electrospun at $25 \mathrm{kV}$ were $1.24 \pm 0.21 \mu \mathrm{m}$ (Fig. 4). This increase in the fiber diameter with a higher voltage can be attributed to an increase in the mass flow $[29,30]$, which led to the formation of thicker fibers. At low applied voltages, the resultant nanofibers were non-uniform and voltage and flow rate were $20 \mathrm{kV}$ and $0.5 \mathrm{~mL} \mathrm{~h}^{-1}$. Insets show the size distribution diagrams of the corresponding fibers.

exhibited the mixture of fibers in both nano- and micron ranges. This may be attributed to the lack of enough polarization to form uniform fibers.

As the second parameter, the influence of tip-tocollector distance was systematically altered. Figure 5 shows the morphology of the nanofibers produced at various tip-to-collector distances. Even though the resultant nanofibers were bead-free and almost uniform, no critical change on the fiber diameter was observed with increasing tip-to-collector distance: For instance, the fibers electrospun at the tip-to-collector distance of $10 \mathrm{~cm}$ had a mean diameter of $1070 \pm 210 \mathrm{~nm}$ and it did not show any significant change (i.e., $1050 \pm 230 \mathrm{~nm}$ ) with increasing the tipto-collector distance to $25 \mathrm{~cm}$. Normally, at higher tip-to-collector distances, the evaporation of the solvent might result in the formation of thinner fibers [31]. However, the evaporation of the solvent molecules during the electrospinning process is also dependent on other factors, such as relative humidity [32] and the volatility of the solvent [33]. As DMF has a high boiling point $\left(153{ }^{\circ} \mathrm{C}\right)$, the volatility of the solvent can be ignored in the formation of thinner 

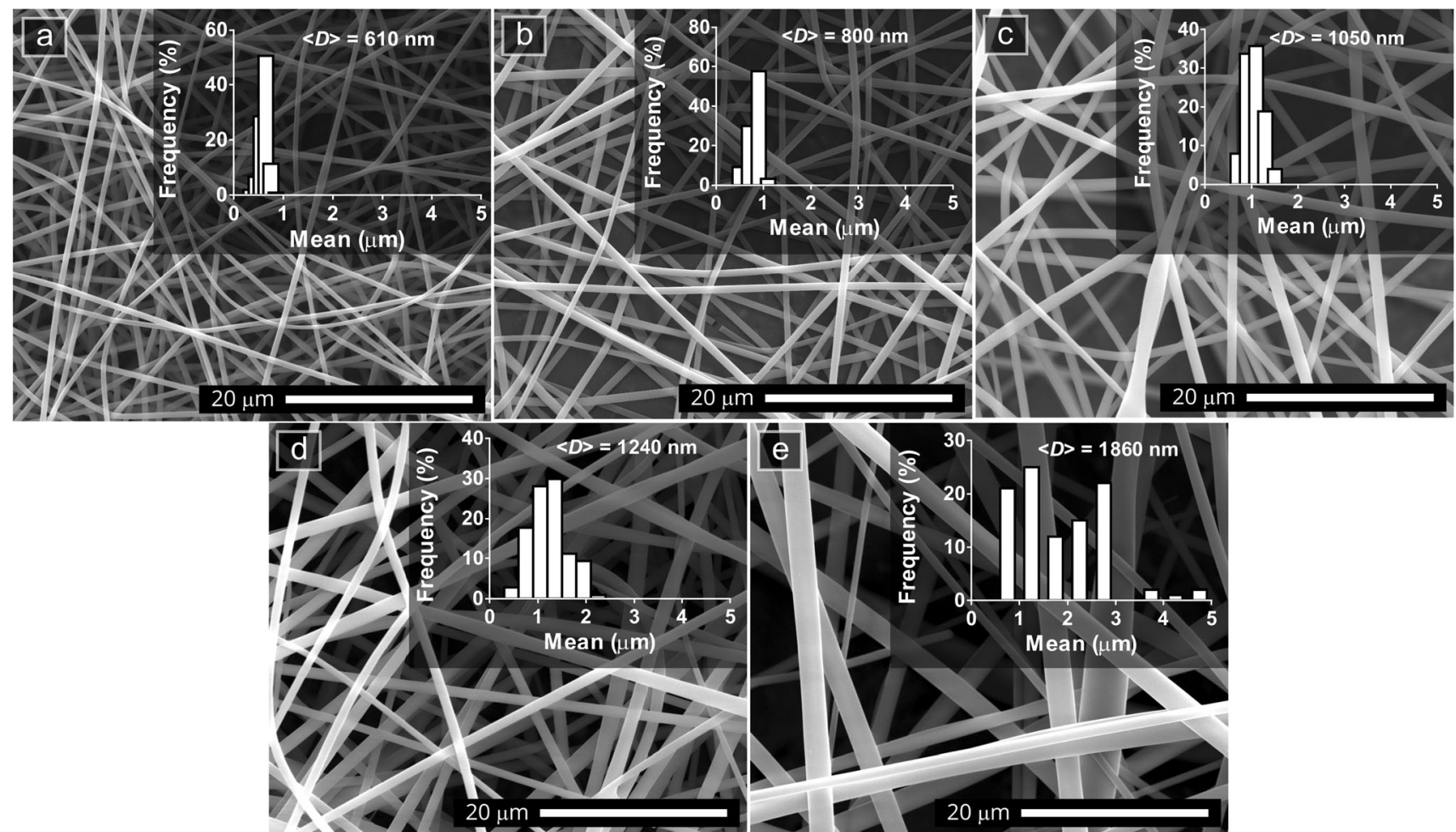

Figure 6 Influence of the flow rate on the morphology of the PAc$\beta$-CD nanofibers electrospun at various flow rates: a $0.1 \mathrm{~mL} \mathrm{~h}^{-1}$, b $0.25 \mathrm{~mL} \mathrm{~h}^{-1}$, c $0.5 \mathrm{~mL} \mathrm{~h}^{-1}, \mathrm{~d} 1 \mathrm{~mL} \mathrm{~h}^{-1}$, and e $2 \mathrm{~mL} \mathrm{~h}^{-1}$. The

nanofibers at elevated tip-to-collector distances. Therefore, we did not observe any noticeable impact of the tip-to-collector distance on the fiber diameter. Higher voltage and shorter distance are generally suggested to increase electrospinning productivity.

Unlike the fibers produced at various applied voltages and TCDs, a most drastic change on fiber properties was observed for the flow rate, and increasing the flow rate substantially enhanced the fiber diameter and led to the formation of the thicker nanofibers and increased fiber size distribution (Fig. 6). The CD nanofibers electrospun at $0.1 \mathrm{~mL} \mathrm{~h}^{-1}$ have a mean diameter of $610 \mathrm{~nm}$, while it increased to $1860 \mathrm{~nm}$ with increasing the flow rate to $2 \mathrm{~mL} \mathrm{~h}^{-1}$. More homogeneous nanofibers were obtained at lower flow rates due to the presence of enough time for polarization [34]. This drastic increase in the fiber diameter can be attributed to a significant increase in the mass flow at higher flow rates. This finding coincides well with the literature reports where increasing flow rate has generally shown an increasing trend in fiber diameter [31, 35-37] and fiber diameter distribution [38].The formation of thinner nanofibers and narrow diameter distribution at lower applied voltage and tip-to-collector distance were $20 \mathrm{kV}$ and $20 \mathrm{~cm}$. Insets show the statistical distribution diagrams of the respective fibers.

flow rates can be explained as follows. Once the flow rate is equivalent to the rate, if the charged jet carries the solution, the shape of the solution on the needle head (i.e., Taylor cone) remains stable without any dripping, and such flow will result in fibers in a narrow diameter range. The high flow rate can cause dripping on the solution and lead to the occurrence of beaded fibers (Figure S2) [39, 40].

The stability of the resultant nanofibers was explored in water and ethanol for 24-h treatment (Fig. 7a). After the treatment with ethanol overnight, the nanofibers were dissolved entirely, whereas the nanofibers treated with water remained intact (Fig. 7b). This intrinsic stability of the nanofibers in water is due to the hydrophobic nature of the nanofibers because of the attached acetyl groups, which could maintain the stability of the nanofibers in water even though their polymer-free nature. The SEM analysis of the respective nanofibers after water treatment for $24 \mathrm{~h}$ revealed unchanged fiber morphology (Fig. 7c, d). Due to the hydrophobic nature of the PAc- $\beta$-CD molecules, the degree of swelling of the resultant nanofibers was negligible, and the nanofibers, unlike most hydrophobic nanofibers, 
Figure 7 Stability of PAc- $\beta$ $\mathrm{CD}$ nanofibers exposed to water and ethanol $\mathbf{a}$ and electrospun mat of the PAc- $\beta$ CD nanofibers after 24-h water exposure b. Scanning electron micrographs of the $\mathbf{c}, \mathbf{d}$ PAc- $\beta$ $\mathrm{CD}$ nanofibers at different magnifications. The inset shows the size distribution diagram for the respective nanofibers.

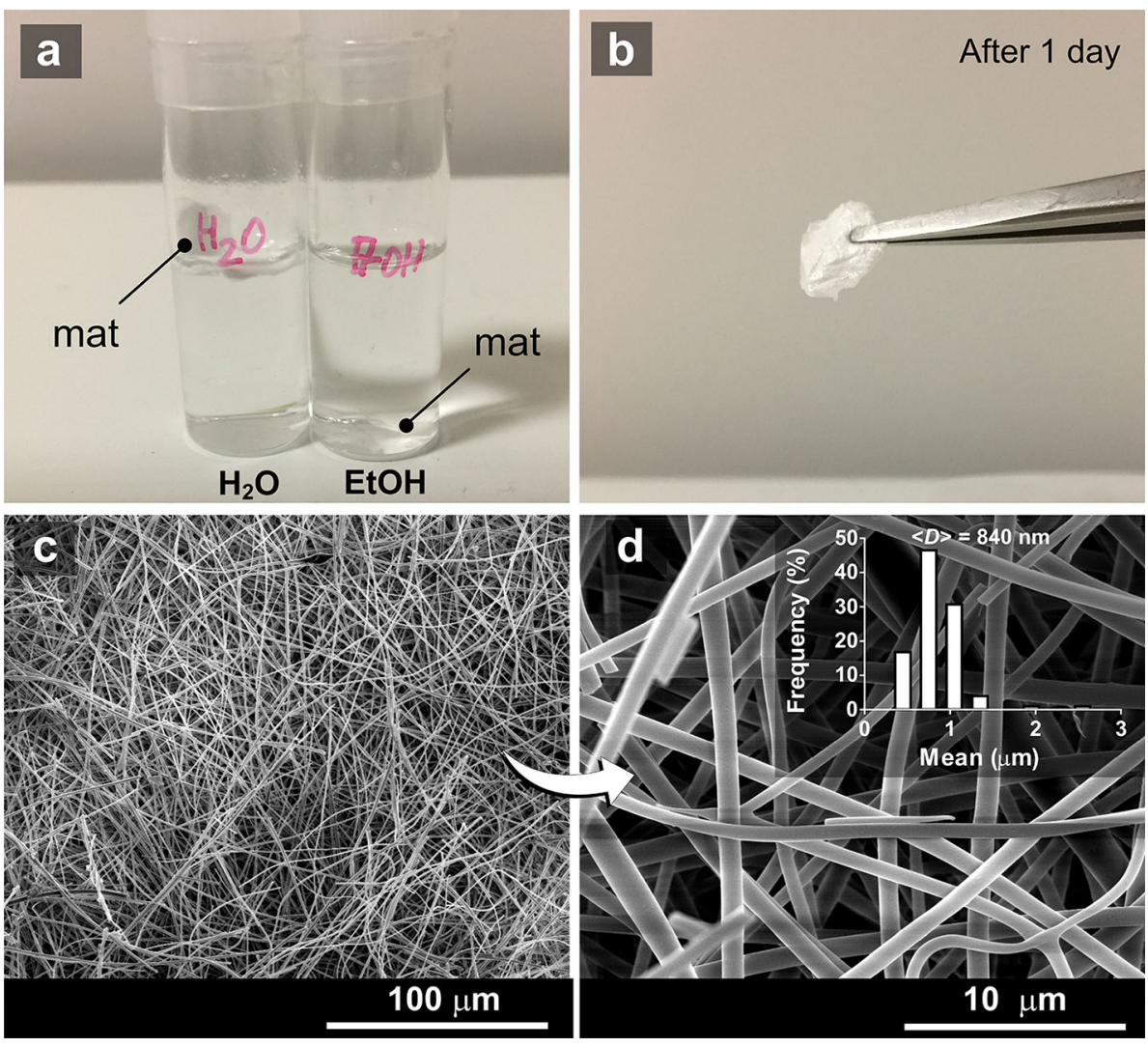

could preserve their rounded nanofiber morphology. The mean nanofiber diameter after water treatment was determined to be $840 \pm 290 \mathrm{~nm}$ (Fig. 7d, inset). However, upon a long-time exposure to water, the dissolution of the nanofibers was observed. This might be attributed to their polymer-free nature and, therefore, the lack of entangled chains to prevent the fiber dissolution.

\section{Conclusion}

Hydrophobic CD nanofibers were successfully produced by the electrospinning of the Pac- $\beta$-CD molecules from DMF solutions. The PAc- $\beta-C D$ was synthesized by the reaction of $\beta$-CD and acetic anhydride by the conversion of hydroxyl groups into acetyl groups, which was confirmed by ${ }^{1} \mathrm{H}-\mathrm{NMR}$. TGA analyses showed enhanced thermal stability of the $\mathrm{CD}$ after the acetyl modification. The variations in the electrospinning process variable affected the nanofiber morphology and diameter and led to the formation of the ultrafine nanofibers by optimization of the electrospinning process variables. At the high flow rates $\left(\geq 0.5 \mathrm{~mL} \mathrm{~h}^{-1}\right)$, the resultant fibers were formed in micron diameter, whereas nanofibers were formed at lower flow rates. The nanofibers remained stable in water and showed no significant morphological change after 24-h water treatment. Owing to the freestanding material structure, PAc- $\beta$-CD nanofibers can be exploited as functional materials for water-based applications, such as water treatment.

\section{Compliance with ethical standards}

Conflict of interest The authors have no other conflicts of interest to declare.

Electronic supplementary material: The online version of this article (https://doi.org/10.1007/s108 53-020-04820-2) contains supplementary material, which is available to authorized users.

\section{References}

[1] Biwer A, Antranikian G, Heinzle E (2002) Enzymatic production of cyclodextrins. Appl Microbiol Biotechnol 59:609. https://doi.org/10.1007/s00253-002-1057-x 
[2] Tabushi I (1982) Cyclodextrin catalysis as a model for enzyme action. Acc Chem Res 15:66. https://doi.org/10.10 21/ar00075a001

[3] Brewster ME, Hora MS, Simpkins JW, Bodor N (1991) Use of 2-hydroxypropyl- $\beta$-cyclodextrin as a solubilizing and stabilizing excipient for protein drugs. Pharm Res 8:792. h ttps://doi.org/10.1023/A:1015870521744

[4] Brewster ME, Loftsson T (2007) Cyclodextrins as pharmaceutical solubilizers. Adv Drug Deliv Rev 59:645. https://d oi.org/10.1016/j.addr.2007.05.012

[5] Wang X, Brusseau ML (1993) Solubilization of some lowpolarity organic compounds by hydroxypropyl-beta-cyclodextrin. Environ Sci Technol 27:2821. https://doi.org/10. 1021/es00049a023

[6] Buschmann HJ, Denter U, Knittel D, Schollmeyer E (1998) The use of cyclodextrins in textile processes: an overview. J Text Inst 89:554. https://doi.org/10.1080/ 00405009808658641

[7] Thatiparti TR, Shoffstall AJ, von Recum HA (2010) Cyclodextrin-based device coatings for affinity-based release of antibiotics. Biomaterials 31:2335. https://doi.org/10.1016/ j.biomaterials.2009.11.087

[8] Celebioglu A, Topuz F, Uyar T (2019) Water-insoluble hydrophilic electrospun fibrous mat of cyclodextrinepichlorohydrin polymer as highly effective sorbent. ACS Appl Polym Mater. https://doi.org/10.1021/acsapm.8b00034

[9] Mellet CO, Fernández JMG, Benito JM (2011) Cyclodextrin-based gene delivery systems. Chem Soc Rev 40:1586. h ttps://doi.org/10.1039/C0CS00019A

[10] Topuz F, Uyar T (2019) Electrospinning of cyclodextrin functional nanofibers for drug delivery applications. Pharmaceutics 11:6. https://doi.org/10.3390/pharmaceutic s11010006

[11] Lee Jung B, Kim JE, Balikov DA et al (2016) Poly(l-lactic acid)/gelatin fibrous scaffold loaded with simvastatin/betacyclodextrin-modified hydroxyapatite inclusion complex for bone tissue regeneration. Macromol Biosci 16:1027. https://d oi.org/10.1002/mabi.201500450

[12] Singh N, Sahu O (2019) In: Shahid ul I, Butola BS (eds) The impact and prospects of green chemistry for textile technology. Woodhead Publishing

[13] Fenyvesi É, Vikmon M, Szente L (2016) Cyclodextrins in food technology and human nutrition: benefits and limitations. Crit Rev Food Sci Nutr 56:1981. https://doi.org/10. 1080/10408398.2013.809513

[14] Ahn Y, Kang Y, Ku M, Yang Y-H, Jung S, Kim H (2013) Preparation of $\beta$-cyclodextrin fiber using electrospinning. RSC Adv 3:14983. https://doi.org/10.1039/C3RA42339E

[15] Celebioglu A, Uyar T (2012) Electrospinning of nanofibers from non-polymeric systems: polymer-free nanofibers from cyclodextrin derivatives. Nanoscale 4:621. https://doi.org/1 0.1039/C1NR11364J

[16] Celebioglu A, Uyar T (2020) Electrospinning of cyclodextrins: hydroxypropyl-alpha-cyclodextrin nanofibers. J Mater Sci 55:404. https://doi.org/10.1007/s10853-019-03983-x

[17] Manasco JL, Saquing CD, Tang C, Khan SA (2012) Cyclodextrin fibers via polymer-free electrospinning. RSC Adv 2:3778. https://doi.org/10.1039/C2RA00004K

[18] Topuz F, Uyar T (2018) Influence of hydrogen-bonding additives on electrospinning of cyclodextrin nanofibers. ACS Omega 3:18311. https://doi.org/10.1021/acsomega.8b02662

[19] Celebioglu A, Yildiz ZI, Uyar T (2017) Electrospun crosslinked poly-cyclodextrin nanofibers: highly efficient molecular filtration thru host-guest inclusion complexation. Sci Rep 7:7369. https://doi.org/10.1038/s41598-017-07547-4

[20] Celebioglu A, Topuz F, Yildiz ZI, Uyar T (2019) Efficient removal of polycyclic aromatic hydrocarbons and heavy metals from water by electrospun nanofibrous polycyclodextrin membranes. ACS Omega 4:7850. https://doi.org/ 10.1021/acsomega.9b00279

[21] Boger J, Corcoran RJ, Lehn J-M (1978) Cyclodextrin chemistry: selective modification of all primary hydroxyl groups of $\alpha$ - and $\beta$-cyclodextrins. Helv Chim Acta 61:2190. https://doi.org/10.1002/hlca.19780610622

[22] Yu HS, Lee JM, Youn YS, Oh KT, Na K, Lee ES (2018) $\gamma$ Cyclodextrin-phenylacetic acid mesh as a drug trap. Carbohydr Polym 184:390. https://doi.org/10.1016/j.carbpol.2017. 12.078

[23] Lei L, Buddingh J, Wang J, Liu G (2020) Transparent omniphobic polyurethane coatings containing partially acetylated $\beta$-cyclodextrin as the polyol. Chem Eng J 380:122554. https://doi.org/10.1016/j.cej.2019.122554

[24] Liu Z-T, Shen L-H, Liu Z-W, Lu J (2009) Acetylation of $\beta$ cyclodextrin in ionic liquid green solvent. J Mater Sci 44:1813. https://doi.org/10.1007/s10853-008-3238-1

[25] Xiao Y, Lim HM, Chung TS, Rajagopalan R (2007) Acetylation of $\beta$-cyclodextrin surface-functionalized cellulose dialysis membranes with enhanced chiral separation. Langmuir 23:12990. https://doi.org/10.1021/la7026384

[26] Sultana T, Jung JM, Hong S-S et al (2012) Characteristic profiles of the inclusion complex of omeprazole/peracylated$\beta$-cyclodextrin formed in supercritical carbon dioxide. J Incl Phenom Macro 72:207. https://doi.org/10.1007/s10847-0119966-х

[27] Topuz F, Satilmis B, Uyar T (2019) Electrospinning of uniform nanofibers of polymers of intrinsic microporosity (PIM-1): the influence of solution conductivity and relative humidity. Polymer 178:121610. https://doi.org/10.1016/j.po lymer.2019.121610 
[28] Topuz F, Uyar T (2017) Electrospinning of gelatin with tunable fiber morphology from round to flat/ribbon. Mater Sci Eng C 80:371. https://doi.org/10.1016/j.msec.2017.06. 001

[29] Demir MM, Yilgor I, Yilgor E, Erman B (2002) Electrospinning of polyurethane fibers. Polymer 43:3303. https://d oi.org/10.1016/S0032-3861(02)00136-2

[30] Li L, Hsieh Y-L (2005) Ultra-fine polyelectrolyte fibers from electrospinning of poly(acrylic acid). Polymer 46:5133. h ttps://doi.org/10.1016/j.polymer.2005.04.039

[31] Heikkilä P, Harlin A (2008) Parameter study of electrospinning of polyamide-6. Eur Polym J 44:3067. https://doi. org/10.1016/j.eurpolymj.2008.06.032

[32] Yang Y, Jia Z, Li Q, Guan Z (2006) Experimental investigation of the governing parameters in the electrospinning of polyethylene oxide solution. IEEE Trans Dielectr Electr Insul 13:580. https://doi.org/10.1109/TDEI.2006.1657971

[33] Wang C (2006) Effect of concentration, voltage, take-over distance and diameter of pinhead on precursory poly (phenylene vinylene) electrospinning. Pigm Resin Technol 35:278. https://doi.org/10.1108/03699420610692887

[34] Li Z, Wang C (2013) In: Li Z, Wang C (eds) One-dimensional nanostructures: electrospinning technique and unique nanofibers. Springer, Berlin
[35] Kidoaki S, Kwon IK, Matsuda T (2006) Structural features and mechanical properties of in situ-bonded meshes of segmented polyurethane electrospun from mixed solvents. J Biomed Mater Res B. https://doi.org/10.1002/jbm.b.30336

[36] Wang C, Hsu C-H, Lin J-H (2006) Scaling laws in electrospinning of polystyrene solutions. Macromolecules 39:7662. https://doi.org/10.1021/ma060866a

[37] Zong X, Kim K, Fang D, Ran S, Hsiao BS, Chu B (2002) Structure and process relationship of electrospun bioabsorbable nanofiber membranes. Polymer 43:4403. https://d oi.org/10.1016/S0032-3861(02)00275-6

[38] Zeng J, Chen X, Xu X et al (2003) Ultrafine fibers electrospun from biodegradable polymers. J Appl Polym 89:1085. https://doi.org/10.1002/app.12260

[39] Haghi AK, Akbari M (2007) Trends in electrospinning of natural nanofibers. Phys Status Solidi A 204:1830. https://d oi.org/10.1002/pssa.200675301

[40] Megelski S, Stephens JS, Bruce CD, Rabolt JF (2002) Micro- and nanostructured surface morphology on electrospun polymer fibers. Macromolecules 35:8456. https://doi. org/10.1021/ma020444a

Publisher's Note Springer Nature remains neutral with regard to jurisdictional claims in published maps and institutional affiliations. 